\title{
Clinical and Socio demographic profile of attendees at ART centre in a tertiary care hospital in Mangalore, India
}

\author{
UB Nayak', S Lenka², B Achappa ${ }^{3}$

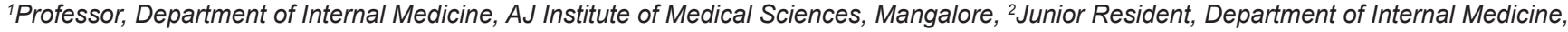 \\ Kasturba Medical College, Mangalore, ${ }^{3}$ Associate Professor, Department of Internal Medicine, Kasturba Medical College, Mangalore (Affiliated \\ to Manipal University) \\ Institute to which the work is affiliated to: Department of Internal Medicine, Kasturba Medical College, Mangalore (Affiliated to Manipal University)
}

\section{A B S T R A C T}

Introduction: India has the third largest number of people living with HIV/AIDS. There is a need to study the profile of patients who come to ART centers and link their clinical and socio-demographic variables in the management. Moreover, it is important to understand the presentation of HIV disease in the local context and culture. The present study is aimed at identifying the socio-demographic characteristics, clinical presentations of HIV/AIDS patients, opportunistic infections and the possible risk factors for acquiring HIV infection at an ART centre of Government Wenlock hospital, situated in Karnataka state of India. Materials and Methods: In this study 102 HIV patients attending the HIV clinic were enrolled and they were followed for a period of one year with relevant investigations. Results: Of 102 patients 69 were males and 33 were females. The mean age of the study subjects at the time of diagnosis was 38.06. Heterosexual contact was the commonest mode of transmission in96 (94.12\%) patients. History suggestive of a risk factor for HIV transmission could not be elicited in $4(3.92 \%)$ patients. Fever $(71.5 \%)$, weight loss $(62.74 \%)$, cough $(51.96 \%)$ and chronic diarrhea $(43.9 \%)$ were the common presenting symptoms. The most common opportunistic infection was oral candidiasis (66.67\%) followed bytuberculosis $(22.54 \%)$ and pneumocystis pneumonia (13.72\%). Significant number of patients $(30.37 \%)$ developed Zidovudine induced anemia and females were more prone for Zidovudine induced anemia as compared to males. CD4 counts of the patients were significantly inversely correlated with the number of symptoms and the number of opportunistic infections. Conclusion: Majority of patients were of low socioeconomic status and in productive age group with heterosexual contact being commonest mode of transmission. Significant number of patients developed Zidovudine induced anemia and females were more prone.

Keywords: HIV, ART Centre, sociodemographic profile
Access this article online Website:

http://nepjol.info/index.php/AJMS DOI: $10.3126 / a j m s . v 6 i 5.11622$

\section{INTRODUCTION}

India has the third largest number of people living with HIV/AIDS. There are an estimated 23.9 lakh people currently living with HIV/AIDS in India with an adult prevalence of 0.31 percent in 2009 as per the 2008-09 HIVestimates. ${ }^{1} \mathrm{HIV}$ has become the first truly international epidemic easily crossing the oceans \& borders. Despite the improved access to antiretroviral therapy (ART) \& care in many regions of the world AIDS has killed millions of people. ${ }^{2} \mathrm{HIV} / \mathrm{AIDS}$ is no longer just a public health issue in India but become one of the most serious socioeconomic \& developmental concerns, because maximum no of reported cases are occurring in sexually active \& economically productive age group (15-44yrs). Deaths of young adults have an especially damaging impact on their families and communities, skills are lost, work force shrinks \& children's are orphaned. ${ }^{3}$ Though, ART does not cure HIV/AIDS, but effective ART regimens inhibit the efficient replication of the HIV virus, and reduce viremiato undetectable levels. The Government of India launched the free ART programme on 1 April 
2004, since then more and more patients are put on ART treatment with rapid expansion of the programme. ${ }^{4}$ Spread of HIV in India is heterogeneous. Most infections occur through heterosexual transmission. ${ }^{1}$ The HIV prevalence among the High Risk Groups, i.e., Female Sex Workers, Injecting Drug Users, Men who have Sex with Men and Transgender is higher than the general population. Adult HIV prevalence at national level has declined from $0.41 \%$ in 2000 to $0.31 \%$ in 2009 .

There is a need to study the profile of patients who come to ART centers and link their clinical and socio-demographic variables in the management. Moreover, it is important to understand the presentation of HIV disease in the local context and culture. The present study is aimed at identifying the socio-demographic characteristics, clinical presentations of HIV/AIDS patients, opportunistic infections and the possible risk factors for acquiring HIV infection at an ART centre of Government Wenlock hospital, situated in Karnataka state of India.

\section{MATERIALS AND METHODS}

The present study was a prospective study conducted at the Government Wenlock hospital, Mangalore. HIV positive patients qualified to be enrolled into the study were those who were newly started on ART between August 2011and August 2013. Total 102 patients were followed for one year. A written informed consent was taken from all the patients. History and physical examination was done and recorded on a pre-designed schedule which included the socio-demographic profile of the patients, mode of transmission, presenting symptoms, opportunistic infections etc. Patients were offered antiretroviral therapy if their CD4 lymphocyte count was less than $<350$ cells $/ \mathrm{ml}$. Trimethoprim-Sulphamethoxazole prophylaxis was given to prevent Pneumocystis Carinii pneumonia in all patients with a CD4 lymphocyte count of $<200$ cells $/ \mathrm{ml}$. The patients were followed up every 3-6 months during which their weight, hemoglobin level and CD4 lymphocyte count were determined. Relevant investigations were done during the follow up period. Data was entered and analyzed using a statistical software package (SPSS version 17.0). Ethical approval was obtained from the Institutional Ethics Committee.

\section{RESULTS}

The distribution of patients according to the age showed that, the maximum number of males $38(55.07 \%)$ as well as females $28(84.84 \%)$ were in the age group of $20-39$ years. Maximum patients i.e. $69(67.64 \%)$ were residing in rural area while $33(32.35 \%)$ in urban area. In the present study, out of 102 patients, $19(18.62 \%)$ were illiterate while $83(81.37 \%)$ were literate. Maximum numbers of illiterate patients were females $(57.9 \%)$ as compared to males (42.1\%). Among the patients studied $77(75.49 \%)$ were married. Most of them were working as laborers/farmer $(50 \%)$, housewife $(15.6 \%)$ and drivers $(8.82 \%)$. Laborers include the agricultural as well as nonagricultural laborers (Table 1). The most common presenting complaints were fever, weight loss, cough and chronic diarrhea (Table 2). As expected majority of the patients belonged to the sexually active age group of 20 to 40 years, commonest mode of acquiring the infection was through heterosexual contact $(94.12 \%)$ (Table 3$)$. None of the patients gave a history of drug abuse or mother to child transmission in present study. Out of the 102 patients, $62(60.78 \%)$ were on ZDV+3TC+NVP combination and $17(16.66 \%)$ were on $\mathrm{ZDV}+\mathrm{LMV}+\mathrm{EFV}($ Table 4$)$.

Oral candidiasis $(66.7 \%)$ was the most common opportunistic infection. Other presentations like tuberculosis, pneumocystis carinii pneumonia, cryptosporidiosis, esophageal candidiasis, herpes zoster

\begin{tabular}{lcc} 
Table 1: Distribution of patients by & Occupation \\
\hline Occupation & Number & Percentage \\
\hline Skilled & 11 & 10.78 \\
Unskilled & 51 & 50 \\
Semiskilled & 8 & 7.84 \\
House wives & 16 & 15.68 \\
Drivers & 9 & 8.82 \\
Business man & 2 & 1.96 \\
Commercial sex worker & 2 & 1.96 \\
\hline
\end{tabular}

\begin{tabular}{lcc}
\multicolumn{3}{l}{ Table 2: Presenting complaints } \\
\hline Presenting complaints & Number & Percentage \\
\hline Fever & 73 & 71.5 \\
Weight Loss & 64 & 62.74 \\
Cough & 53 & 51.96 \\
Weakness & 32 & 31.37 \\
Anorexia & 28 & 27.4 \\
Diarrhoea & 22 & 21.56 \\
Breathlessness & 17 & 16.6 \\
Lymphadenopathy & 17 & 16.6 \\
Headache & 12 & 11.76 \\
Pain abdomen & 9 & 8.8 \\
Myalgia & 4 & 3.92 \\
Seizure & 4 & 3.92 \\
Odynophagia & 8 & 7.84 \\
Jaundice & 3 & 2.94 \\
\hline
\end{tabular}

Table 3: Mode of transmission

\begin{tabular}{lcc} 
Mode of transmission & No. of patients & Percentage \\
\hline Heterosexual & 96 & 94.12 \\
Homosexual & 1 & 0.98 \\
Blood transfusion & 1 & 0.98 \\
Not specified & 4 & 3.92 \\
\hline
\end{tabular}


and toxoplasmosis were noted (Table 5). As the number of CD4 count decreased, incidence and the number of opportunistic infections per patient increased. As per the WHO staging $49(48.03 \%)$ patients were in stage 3 (Table 6). Of the 79 patients on Zidovudine based regimens 24 (30.37\%) patients developed Zidovudine induced anemia. Out of 24 patients who developed Zidovudine induced anemia 14 were males and 10 were females (Table 7). Of the 78 patients on Nevirapine based regimens 6(5.88\%) developed allergic reactions and $3(2.94 \%)$ patients developed Steven Johnson syndrome for which regimens were changed.

\section{DISCUSSION}

The overall male patients (67.64) outnumbered female $(32.35 \%)$ patients and male to female ratio is $2.09: 1$. In the NACO annual report 2011-12 sex distribution shows $56.6 \%$ males and $39 \%$ females. Male preponderance was also observed in the study conducted by Ahmad et al ${ }^{5}$

\begin{tabular}{lcc}
\multicolumn{3}{l}{ Table 4: Regimens initiated } \\
\hline Regimens initiated & Frequency & Percentage \\
\hline ZDV+LMV+NVP & 62 & 60.78 \\
ZDV+LMV+EFV & 17 & 16.66 \\
STV+LMV+NVP & 16 & 15.68 \\
STV+LMV+EFV & 7 & 6.86 \\
\hline
\end{tabular}

\begin{tabular}{lcc} 
Table 5: Opportunistic infections & \\
\hline Opportunistic Infections & Number & Percentage \\
\hline Oral candidiasis & 68 & 66.7 \\
Tuberculosis & 23 & 22.54 \\
Pcp & 14 & 13.72 \\
Cryptosporidiosis & 12 & 11.76 \\
Toxoplasmosis & 3 & 2.94 \\
Oesophageal candidiasis & 11 & 10.78 \\
Herpes zoster & 7 & 6.86 \\
Molluscumcontagiosum & 2 & 1.96 \\
Bacterial pneumonia & 14 & 13.72 \\
\hline
\end{tabular}

\begin{tabular}{lcc}
$\begin{array}{l}\text { Table 6: Number of patients in different WHO } \\
\text { clinical stages }\end{array}$ \\
\hline WHO stage & Number & Percentage \\
\hline Stage 1 & 14 & 13.72 \\
Stage 2 & 21 & 20.58 \\
Stage 3 & 49 & 48.03 \\
Stage 4 & 18 & 17.64 \\
\hline
\end{tabular}

\begin{tabular}{lcc}
$\begin{array}{l}\text { Table 7: Zidovudine induced anemia and gender } \\
\text { distribution }\end{array}$ & & \\
\hline Gender & Not developed ZIA & Developed ZIA \\
\hline Males & 55 & 14 \\
Females & 24 & 10 \\
Total & 79 & 24 \\
\hline
\end{tabular}

and Singh et al. ${ }^{6}$ In this study age distribution showed highest incidence in the age group 18-49 (90.2\%) which was similar to NACO annual report 2011-12 which states that incidence is highest in 15-49 (83\%) age group which indicates that maximum were in sexually active and productive age group. Similar results were seen in study done by Sonani et al. ${ }^{4}$

In the present study out of 102 patients, $83(81.37 \%)$ were literate while $19(18.62 \%)$ were illiterate. Among literate maximum number of patients i.e.49 (48.04\%) were educated upto secondary school. These findings were more or less similar to study conducted by Joshi et $\mathrm{al}^{7}$ and Joge et al. ${ }^{8}$

Maximum patients i.e.69 (67.64\%) were residing in rural area while $33(32.35 \%)$ in urban area. Similar findings were reported by Joardar et $\mathrm{al}^{9}$ and Joge et $\mathrm{al}^{8}{ }^{8}$ With regard to marital status majority of patients were married (75.49\%). High number of married persons having HIV/AIDS was also reported by Jayrama $(70.3 \%) .{ }^{10}$ Of the 69 male patients, only $3(4.34 \%)$ had circumcised penis. According to Scabo and Short ${ }^{11}$ male circumcision provides two fold to eight fold protective effect against HIV. The present study shows very less percentage of HIV cases are having circumcised penis.

The predominant mode of transmission was through unprotected heterosexual intercourse $(94.12 \%)$. More or less similar findings were reported by Gupta ${ }^{12}$ (97\%) and Kothari. ${ }^{13}$ But findings were not in accordance with Singh et $\mathrm{al}^{6}$ who reported intravenous drug abuse (53.71\%) as the predominant mode of transmission. Chakravarty et al ${ }^{14}$ also found that the most common mode of transmission was heterosexual $(80.04 \%)$. As far as risk factors are concerned, two female patients were Commercial sex workers (CSW), and only one male patient gave history of men having sex with men (MSM), the reason could be the social taboos associated with the practice of these risk factors.

Out of 102 patients 62(60.78\%) were started on ZDV+LMV+NVP regimen followed by $17(16.66 \%)$ on $\mathrm{ZDV}+\mathrm{LMV}+\mathrm{EFV}$ regimen,16(15.68\%) on $\mathrm{STV}+\mathrm{LMV}+\mathrm{NVP}$ regimen and $7(6.86 \%)$ on $\mathrm{STV}+\mathrm{LMV}+\mathrm{EFV}$ regimen. In a study done by Deshpande et al ${ }^{15} 47.26 \%$ patients were started on ZDV+LMV+NVP, $31.51 \%$ were started on STV+LMV+NVP, $10.28 \%$ were started on ZDV+LMV+EFV and $10.95 \%$ were started on STV+LMV+EFV regimen. In a study done by Bachani et $\mathrm{al}^{16} 71 \%$ of patients were started on STV $+3 \mathrm{TC}+\mathrm{NVP}$ and ZDV+3TC+NVP was prescribed to $28 \%$ of the patients. In present study $49(48.03 \%)$ patients were in WHO clinical stage 3 which was similar to a study done by Deshpande et al ${ }^{15}$ where $42.77 \%$ patients were in stage 3 . 
Oral candidiasis $(66.7 \%)$ was the commonest opportunistic infection followed by tuberculosis $(22.54 \%)$ in our study which was different from the study done by Deshpande et $\mathrm{al}^{15}$ where tuberculosis $(62 \%)$ was the commonest opportunistic infection. Chakravarty et $\mathrm{al}^{14}$ also reported tuberculosis $(38.8 \%)$ to be the most common opportunistic infection, followed by candidiasis $(20.3 \%)$ and diarrhea $(12.7 \%)$ which does not match our observation. As the number of CD4 cells decreased, incidence and the number of opportunistic infections per patient increased and a highly significant inverse correlation has been observed between the two variables $(p<0.001)$. Similar results were seen in study done by Chakravarty et al. ${ }^{14}$

We found that fever was the most common presenting complaint followed by weight loss and cough and was comparable with previous studies done by Boruah et $\mathrm{al}^{17}$, Tsega ${ }^{18}$ and Deshpande et al. ${ }^{15}$ Though numerous other studies have reported about some other complaints like problem in conception ${ }^{19}$, fertility ${ }^{20}$ and neurological disorders $^{21}$ we did not note any such problems in our patients.

Out of total 79 patients on Zidovudine based regimens 24(30.37\%) developed Zidovudine induced anemia which was statistically significant $(\mathrm{p}<0.001)$. Similar results were seen in a study done by Rajesh $\mathrm{R}$ et al ${ }^{22}$ where it was $34.54 \%$ but, Agarwal et $\mathrm{al}^{23}$ in his study found Zidovudine induced anemia in only $16.2 \%$ of patients. The mean time for the development of anemia was comparable to other studies. In majority of our patients, anemia developed within 6 months of start of therapy as reported in other studies. ${ }^{24-26}$

Zidovudine induced anemia developed in 14 out of 55 males and 10 out of 24 female patients who were on Zidovudine based regimens. Maximum number of female patients (41.67\%) on Zidovudine based regimens developed anemia when compared to males $(25.45 \%)$ and results were comparable to study done by Agarwal et al. ${ }^{23}$ Out of total 78 patients who were on Nevirapine based regimens 3(2.94\%) patients developed Nevirapine induced Steven Johnson syndrome and 6(5.88\%) developed Nevirapine induced allergy which was not statistically significant. Majority of patients presented with an initial CD4 count of less than 300 cells $/ \mu \mathrm{l}$ which was consistent with the studies done by Sharma et $\mathrm{al}^{27}$ and Deshpande et al. ${ }^{15} \mathrm{We}$ found that CD4 count increased after 6 months and 1 year which was statistically significant $(\mathrm{p}<0.001)$ and more or less similar to the results of Chakravarty et al. ${ }^{14}$

\section{CONCLUSION}

Our study found that most of the affected population was from reproductive age group which increases the economic burden and affects the overall development of the family, community and country. Labourer, which was the most common occupation found to be affected acts as a link population between high risk groups to general population and between urban and rural areas. Heterosexual route was the commonest mode of transmission. Fever, weight loss and cough were the most frequent presenting symptoms and oral candidiasis was the most common opportunistic infection. Significant number of patients $(30.37 \%)$ $(\mathrm{p}<0.001)$ developed Zidovudine induced anemia. Females were more prone for Zidovudine induced anemia when compared to males. Most of the patients developed anemia within 6 months of start of therapy.

\section{REFERENCES}

1. NACO, Annual report 2011-12, Ministry of Health and Family Welfare, Government of India.

2. HIV \& AIDS statistics commentary. UNAIDS/WHO AIDS epidemic update,November 2007. Available at http://www.avert. org.

3. Kishore J. National Health programmes of India. $6^{\text {th }}$ ed, Century publications, New Delhi. 2006, pp138.

4. Sonani HP, Undhad AM and Savani GT. Clinical and sociodemographic profile of patients registered at ART centre, Smimer, Surat. National Journal of Community Medicine 2011; 2(1):130-132.

5. Ahmad Z, Zaheer MS, Rabbani MU, Khan T, Rewari BB and Pandey DK. Clinical and Demographic Profile of Patients of AIDS in and around Aligarh. Journal of Indian Academy of Clinical Medicine 2003; 4(2):121-126.

6. Singh HR, Singh NGB and Singh TB. Estimation of CD4+ and CD8+ Lymphocytes in HIV Infection and AIDS Patients in Manipur. Indian journal of medical microbiology 2007; 25 (2):126-132.

7. Joshi HS, Das R and Agnihotri AK. Clinico epidemiological Profile of HIV /AIDS Patients in Western Nepal- a Study from a Teaching Hospital. Indian Journal of Preventive and Social Medicine 2004; 35(1) \& (2): 69-76.

8. Joge US, Deo DS, Lakde RN, Choudhari SG, Malkar VR and Ughade HH. Sociodemographic and clinical profile of HIVIAIDS patients visiting to ART Centre at a rural tertiary care hospital in Maharashtra state of India Int J Biol Med Res 2012; 3(2): 15681572.

9. Joardar GK, Sarkar A, Chatterjee C, Bhattacharya RN, Sarkar S and Banerjee P. Profiles of Attendees in the VCTC of North Bengal Medical College in Darjeeling of West Bengal. Indian Journal of Community Medicine 2006; 3(4):239-240.

10. Jayarama S, Shenoy S, Unnikrishnan B, Ramapuram J and Rao M. Profiles of Attendees in VCTC of a Medical College in Coastal Karnataka. Indian Journal of Community Medicine 2008; 33(1): 43-46.

11. Szabo R and Short RV. How does male circumcision protect against HIV infection? BMJ 2000; 320:1592-1594.

12. Gupta V, Singla N, Lehl SS and Chander J. Clinicoepidemiological Profile of HIV Infection over a Period of Six Years in a North Indian Tertiary Care Hospital. Indian Journal of Med Microbol 2007; 25:171.

13. Kothari K and Goyal S. Study of clinical presentation, spectrum of systemic involvement and op-portunistic infections in AIDS patients. J Assoc Physicians Ind 2001; 49: 435-438. 
14. Chakravarty J, Mehta H, Parekh A, Attili SVS, Agrawal NR, Singh SP, et al. Study on Clinico-epidemiological Profile of HIV Patients in Eastern India. J Assoc Physicians Ind 2006; vol.54.

15. Deshpande JD, Giri PA and Phalke DB. Clinico-epidemiological profile of HIV patients attending ART centre in rural Western Maharashtra, India. South East Asia Journal of Public Health 2012; 2(2):16-21.

16. Bachani D, Garg R, Rewari B, Hegg L and Deshpande A. Twoyear treatment outcomes of patients enrolled in India's national first-line antiretroviral therapy programme. Natl Med J India 2010; 23:7-12.

17. Boruah PK and Adhikari AK. Clinical spectrum of HIVIAIDS presenting to Gauhati Medical College. J Assoc Physicians Ind 2003; 51:1258-1260.

18. Tsega E. The demographic, social and clinical presentations of one hundred Ethiopian patients with HIV infection. Ethiop Med J 1990; 28:81-88.

19. Setel P. The effects of HIV and AIDS on fertility in East and Central Africa. Heal Trans Rev 1995; 5:179-189.

20. Sengupta P. Health impacts of yoga and Pranayama: A state-ofthe-art review. Int J Prev Med 2012; 3:444-458.

21. Longer SK. HIV-AIDS survival raises likelihood of neurological problems. Neurol Today 2003; 3: 38-40.
22. Rajesh R, Vidyasagar S, Varma DM, Mohiuddin S, Noorunnisa Evaluation of incidence of zidovudine induced anemia in Indian human immunodeficiency virus positive patients in comparison with stavudine based highly active antiretroviral therapy. Int J Risk Saf Med. 2011;23(3):171-80. doi: 10.3233/JRS-2011-0531.

23. Agarwal D, Chakravarty J, Chaube L, Rai M, Agrawal NR and Sundar S. High incidence of zidovudine induced anaemia in HIV infected patients in eastern India. Indian J Med Res 2010; 132 386-389.

24. Isaakidis P, Raguenaud ME, Phe T, Khim SA, Kuoch S, Khem S, et al. Evaluation of a systemic substitution of zidovudine for stavudine-based HAART in a program setting in rural Combodia. J Acquir Immune Defic Syndr 2008; 49: 48-54.

25. vanLeeuwen R, van den Hurk PJ, Jöbsis GJ, van der Wouw8. PA, Reiss P, Eeftinck Schattenkerk JK, et al. Failure to maintain high-dose treatment regimens during long-term use of zidovudine in patients with symptomatic human immunodeficiency virus type 1 infection. Genitourin Med 1990; 66: 418-422.

26. Hoffmann $\mathrm{C}$ and Mulcahy F. Overview of antiretroviral agents. In:HIV medicine $14^{\text {th }}$ edition. Hoffmann C, Rockstroh JK, Kamps BS (editors). Paris: Flying Publisher; 2006. p. 94-130.

27. Sharma SK, Kadhiravan T, Banga A, Goyal T, Bhatia I and Saha PK. Spectrum of clinical disease in a series of 135 hospitalized HIV-infected patients from north India. BMC Infect Dis 2004;4:52. 